\title{
A spectrum of assessments
}

\author{
Rina Shvartsman and Stephen Abblitt \\ KeyPath Education
}

\begin{abstract}
Different methods of assessment are used to measure learning outcomes in different academic disciplines. Many learning designers, despite being predisposed to certain assessment methods as they draw on their own specific academic background, work with a broad range of academic disciplines. This can result in difficulties advising academics from a discipline with which they are less familiar on best-practice teaching, learning, and assessment. This paper offers a tool for learning designers and subject matter experts to use when working together to design assessments in various academic courses, based on the characteristics of subject matter within the relevant disciplines. Specifically, we map a set of disciplines and a set of assessment methods on two axes: Pure vs. Applied and Hard vs. Soft (PAHS). For the set of disciplines, we can justify our choice of map locations based on attributes required by relevant accreditation organisations. The scattering of the assessment methods on the map is based on a proposed taxonomy of assessment design and common practice as observed by the authors. Learning designers are encouraged to refer to this paper as a guide when designing assessments for courses outside their knowledge domain.
\end{abstract}

Keywords: Academic disciplines, assessment, learning design, taxonomy

\section{Introduction}

Online and technology-enhanced learning has grown rapidly over the past two decades, and even more so in the pandemic-affected 2020. Consequently, the role of the learning designer has become more common and much more important. Alongside massive capital investments in learning technologies and other digital infrastructures, institutions have also established and/or greatly expanded their own learning design teams or departments to help support their online and blended/hybrid programs. Universities around the world also partner with Online Program Management (OPM) companies to enhance their learning design capabilities, and to design and deliver online courses.

Keypath Education is one such OPM. Operating in the US, Canada, UK, Australia, and Asia, we provide an endto-end suite of services that help universities launch new online programs and reach new students-including, crucially, learning design. In Australia, Keypath Education employs more than 30 staff in learning design and development, now working with ten Australian and Asian universities on more than 40 degree programs. Over the past five years, we have designed and delivered thousands of individual courses, across a wide variety of disciplines - from business and management to the behavioral and social sciences, law, education, nursing, and increasingly science, technology, engineering, and mathematics.

In this context, academics and learning designers (LDs) must establish a highly collaborative working relationship during online course development. The academic brings to this partnership their extensive subject matter expertise, and often a great deal of teaching experience; the LD brings their pedagogical, technical and design expertise to bear on designing learning outcomes, assessment tasks, learning activities and course materials. Partly due to the relative newness of the role, LDs come from highly diverse backgrounds and with a variety of quite different experiences (Slade et al., 2018, 2019). Moreover, there are often different requirements from the role in different contexts (Mitchell et al., 2017; Bissett, 2019). This diversity is a clear strength of our profession, but, problems can and do arise when an LD works in a discipline with which they are unfamiliar or inexperienced. For instance: communication challenges may arise when the academic uses jargon; underlying assumptions could be misunderstood by the LD; or, their views on what's normal, what's good and what's sensible could simply be too different, or diverge too far from the characteristics of the subject matter.

When it comes to interdisciplinary collaboration for course design, a major challenge is determining a practical and effective method of assessment. There is a vast spectrum of assessment methods: research projects, short quizzes, design portfolios, etc.; the average LD and academic, only having been exposed to a small portion of the assessment spectrum, are likely to find it difficult to recognise and to recommend new and different assessment methods best suited to a new course modality, discipline and the characteristics of its subject matter. 
Take for example an LD who has a background in Sociology working on a Computer Science course. They might be challenged to understand the context, the appropriateness of the scope and the time it should normally take to complete suggested assessments, and they might wonder to which extent these assessments would align with the learning outcomes of the course. As much as we pride ourselves on empathising, listening, and learning about the disciplines with which we work, it would remain a challenge for the Sociology-backgrounded learning designer to brainstorm and propose original assessments that would inspire the Computer Science academic.

This may lead to the learning designer being less active or effective in the collaboration. This paper aims to equip LDs with a simple, yet useful, tool for communication with the academic about assessment design.

\section{Background}

Assessment powerfully frames how students learn and what they achieve (Snyder, 1971; Kniveton, 1996; Sambell \& McDowell, 1998; Gibbs, 1999; Gibbs \& Simpson, 2004). Assessment will capture and focus students' time and attention, allowing academics and learning designers to direct and shape their learning experience. Assessment matters - and this tendency intensifies in online learning. Good assessment design naturally begins with the end in mind. We apply a "backwards design" (Wiggins \& McTighe, 1998) approach to course design, and assessment design itself follows a similar outcomes-based approach:

1. First, identify the knowledge, skills and outcomes the student must demonstrate.

2. Second, determine the conditions under which the student must demonstrate their knowledge and skills.

3. Third, determine the performance standards, assessment criteria, and evidence to be collected.

4. Fourth, identify the assessment method the student will use to demonstrate their knowledge and skills.

The same learning outcomes can be demonstrated in many ways, and performance standards and assessment criteria adapted accordingly. Similarly, while assessment conditions establish the parameters of assessment, within each of these assessment conditions, several assessment methods may be appropriate. How do we best recognise and recommend right assessment method for the knowledge and skills we are trying to assess?

Research on approaches to teaching and learning (Trigwell et al., 1999; Kember \& Kwan, 2000) is invaluable to the work LDs do in understanding and adapting to an academic's personal pedagogical preferences. More recent research has sought to better understand disciplinary differences in university teaching (Neumann, 2001; Neumann et al., 2002), or the different disciplinary contexts in which learning and teaching occur (LindblomYlänne et al., 2006), as well as the signature pedagogies of the professions (Shulman, 2005).

Relatedly, of interest is research into the differing characteristics of subject matter across the academic disciplines (Biglan, 1973a, 1973b). This includes how different disciplines conceptualise their domain knowledge (Alexander \& Judy, 1988; Sternberg, 1989; Alexander, 1992; Donald, 1995; Buehl \& Alexander, 2001; Muis et al., 2006) and the different epistemological beliefs which drive research as well as teaching and learning within the academic disciplines (Schommer, 1994; Schommer \& Walker, 1995; Hofer \& Pintrich, 1997; Hofer, 2000; SchommerAikens et al., 2003; Hofer \& Bendixen, 2012; Päuler-Kuppinger \& Jucks, 2017).

Since a purpose of assessment is to provide evidence of knowledge and associated skills acquired by the student, our contention is that by better understanding the characteristics of the subject matter within an academic discipline, we can more readily determine the most effective assessment method for a given context. This allows LDs to quickly move beyond their initial preconceptions when commencing work in a new or unfamiliar discipline and engage in more productive conversations with academics about assessment.

\section{Method}

In this paper we introduce the idea of the spectrum of assessments in three stages: initially, we map a set of disciplines on a 2-dimensional plane with the two axes being, adapted in-part from Biglan's classification of academic disciplines (Biglan, 1973a, 1973b): Pure to Applied (horizontal axis) - PA; Hard to Soft (vertical axis) - HS. We denote this map as PAHS. We then map a set of assessment methods on the same PAHS axes. Finally, we demonstrate the result of the two maps being mashed up together.

The PAHS map can serve as a framework for determining what assessment methods are potentially suitable for a certain discipline - based on their relative proximity on the mash-up map. This comes with the disclaimer that proximity does not guarantee suitability, nor the opposite is true; drawing conclusions from the mash-up PAHS map should be done with careful consideration. Importantly, the specific numbers used here to position points on 
the map are made up for demonstration purpose only. Positioning a discipline or an assessment method on the PAHS map by an individual involves a great deal of generalisation and subjective judgement, but when done by a large cluster of people, the average position is more meaningful. With this in mind, and with the vision of collecting survey responses and creating a rich database of rankings, both from LDs and academics, we aim to produce a data based PAHS map in the future.

We supply a link to the Excel spreadsheet in which all our plots were generated for the ease of use by LDs wishing to utilise this framework in their practice. To utilise the framework for a new type of assessment or an academic discipline that is not listed, one needs to determine their coordinates on the plot and augment the data by inputting these coordinates accordingly. Explanation on how to add new data and/or modify existing data is found within the spreadsheet. Furthermore, one can utilise the bubble sizes to serve a certain purpose.

\section{Academic Disciplines}

There is a vast number of academic disciplines, each branching off to further fields of knowledge. Research, practice, and technological advancement push the boundaries of knowledge and lead to the establishment of new niches each day. Scattering the different disciplines along the two axes of Pure to Applied (horizontal axis) and Hard to Soft (vertical axis) can be a useful conceptualisation strategy to later be repeated for assessment methods. We begin by explaining about the axes and the rationale behind assigning the coordinates to the various disciplines. See Figure 1 for the scattering of the demonstrative set of disciplines. The various disciplines (small bubbles) are grouped into the following five groups (big bubbles): Humanities (yellow), Social Sciences (green), Natural Sciences (blue), Formal Sciences (purple), and Applied Sciences (red). The coordinates used for the scatter plot are bounded between -2 to +2 .

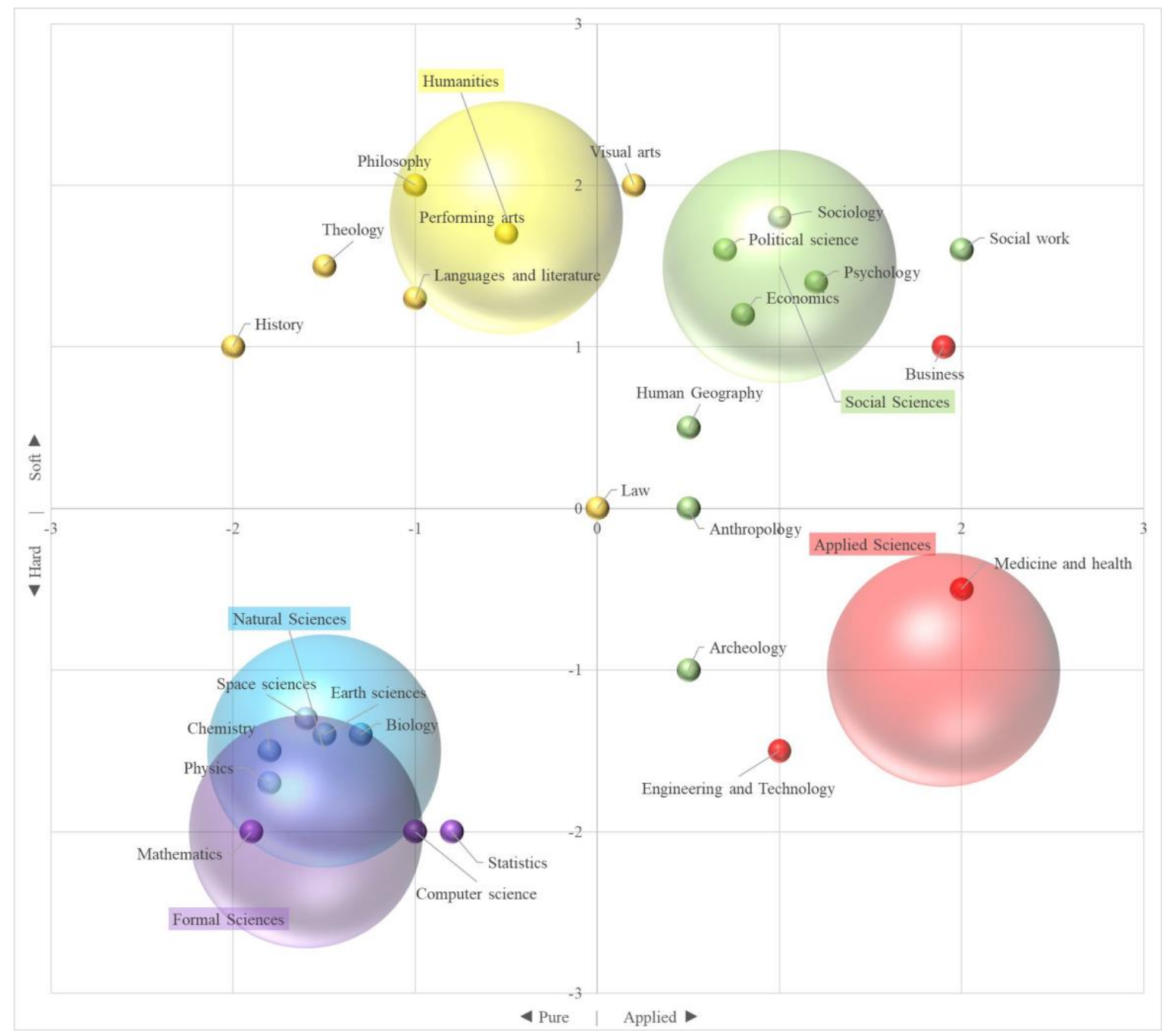

Figure 1: Various academic disciplines scattered on the PAHS map 


\section{Pure vs. Applied Disciplines}

We label a discipline 'pure' if it is predominantly associated with knowledge that in and of itself is not concerned with application to practical problems. On the other end, we label a discipline 'applied' if it is largely concerned with knowledge that is put into practice. Arguably, all knowledge can carry a potential for being used in some application, however, the distinguishing criterion is that knowledge in the 'applied' disciplines is produced to be used and applied to practical and real-world problems in the present. It is easier to locate the extremes of the spectrum than deciding how to position a semi-applied discipline. As a guide, consider "how is this body of knowledge being used nowadays?".

History is an example of a discipline that is not often applied to solve problems. Therefore, we located History on the -2 coordinate (purest) on the map. On the other end of the spectrum, we positioned the discipline of Medicine and Health on the +2 coordinate (most applied), since attempts to find solutions to existing health problems are the driving force of this discipline. Another option is to reference accreditation bodies. For instance, Engineers Australia specifies 16 competency standards for professional engineers: 6 standards are related to Knowledge and Skill Base, 4 to Engineering Application Ability, and 6 to Professional and Personal Attributes (Engineers Australia, 2019). This indicates that Engineering is a combination of both "pure" (knowledge and understanding) and "applied" (application and professional conduct) characteristics.

\section{Hard vs. Soft Disciplines}

The hard-to-soft scale is useful to distinguish between disciplinary approaches to knowledge: the 'hard', or more "scientific", disciplines are characterised by a dominant paradigm or an agreed upon body of theory; the 'soft' disciplines can entertain multiple paradigms and perspectives, philosophies, ideas and hypotheses that do not necessarily require proving or disproving. The distinction is between the positivist/objectivist paradigms which dominate the 'hard' sciences and the more interpretivist and subjectivist paradigms predominating in the arts, humanities, social sciences, and other 'soft' disciplines.

Disciplines in which an idea or information is required to be backed up with evidence or a rigorous logical proof for it to hold relevant, are considered hard disciplines and are closer to -2 on the hard-to-soft scale. Disciplines that embrace a variety and richness of ideas, opinions, theories, methods and techniques - all of which can stand in contradiction to one another - are closer to +2 on the hard-to-soft scale.

Take for instance Business and Economics: two disciplines which involve clusters of contested approaches, models, theories, and paradigms, all of which enjoy a right of existence, despite some being mutually contradictory. They encompass actively debated topics such as ethics, global economy, management strategies, productivity, sustainability, and innovation. The learner is often introduced to a set of plausible concepts which they can either accept (potentially with adaptations) or not. The lack of an absolute single consensus or truth for much of the knowledge in these disciplines is the reason they rank quite 'soft' on the hard-to-soft axis.

Mathematics is an example of one the 'hardest' disciplines on our map. Despite much of the mathematics discipline relying on a set of axioms, it always aims to rely on as little axioms as possible and pave the way to conclusions and results through precise, rigorous and logical arguments. Arguments that are lacking in reasoning are of little interest or attention in mathematics, no matter how useful; to be a successful mathematician one must prove something is correct by means of logical deduction. Any new definitions must be useful for explaining proofs or else they are deemed unnecessary.

\section{Assessment Methods}

Figure 2 presents a set of assessment methods (small bubbles) scattered on the Pure vs. Applied and Hard vs. Soft axes. We divided the various assessment methods into 5 groups (large bubbles): Design, creation or production of new work or artifacts (yellow); Critical analysis and/or evaluation of information/facts and others' work (green); Reflection and general engagement (blue); Demonstration of acquisition of knowledge (purple); Application of knowledge and practice of techniques/skills (red).

We note that the Revised Bloom's Taxonomy of Educational Objectives (Anderson \& Krathwohl, 2001; Krathwohl, 2002) has inspired the above grouping. The first group (yellow) relates predominantly to the 'Create' category. It includes tasks such as constructing an architectural model or a computer-aided design, composing an original musical piece, or producing an animation clip. The second group (green) relates to both the 'Analyse' and the 'Evaluate' categories. Examples of assessments in this group include writing an annotated bibliography, a peer 
review or carrying out a research project. The third group (blue) is similar to the green group, however it involves tasks that are more self-focused, or metacognitive, like a blog post or self- assessment. It also includes group work because it often leads the group members to apply some self-assessment ("how can I contribute?"), as well as observation and note-taking, debating, etc. The fourth group (purple) relates to the 'remember' and 'understand' categories. Short-answer questions, multiple-choice questions, and an oral test are some examples of assessment methods in this group. The fifth group (red) relates to the 'Apply' category. It covers more experiential tasks such as lab work and apprenticeship, as well as problem-solving tasks such as a problem set.

These groups are not mutually exclusive, for example, an opinion piece is both relating to evaluation of oneself ("what is my opinion on a certain topic?") and is a creative work (expression of the opinion in writing).

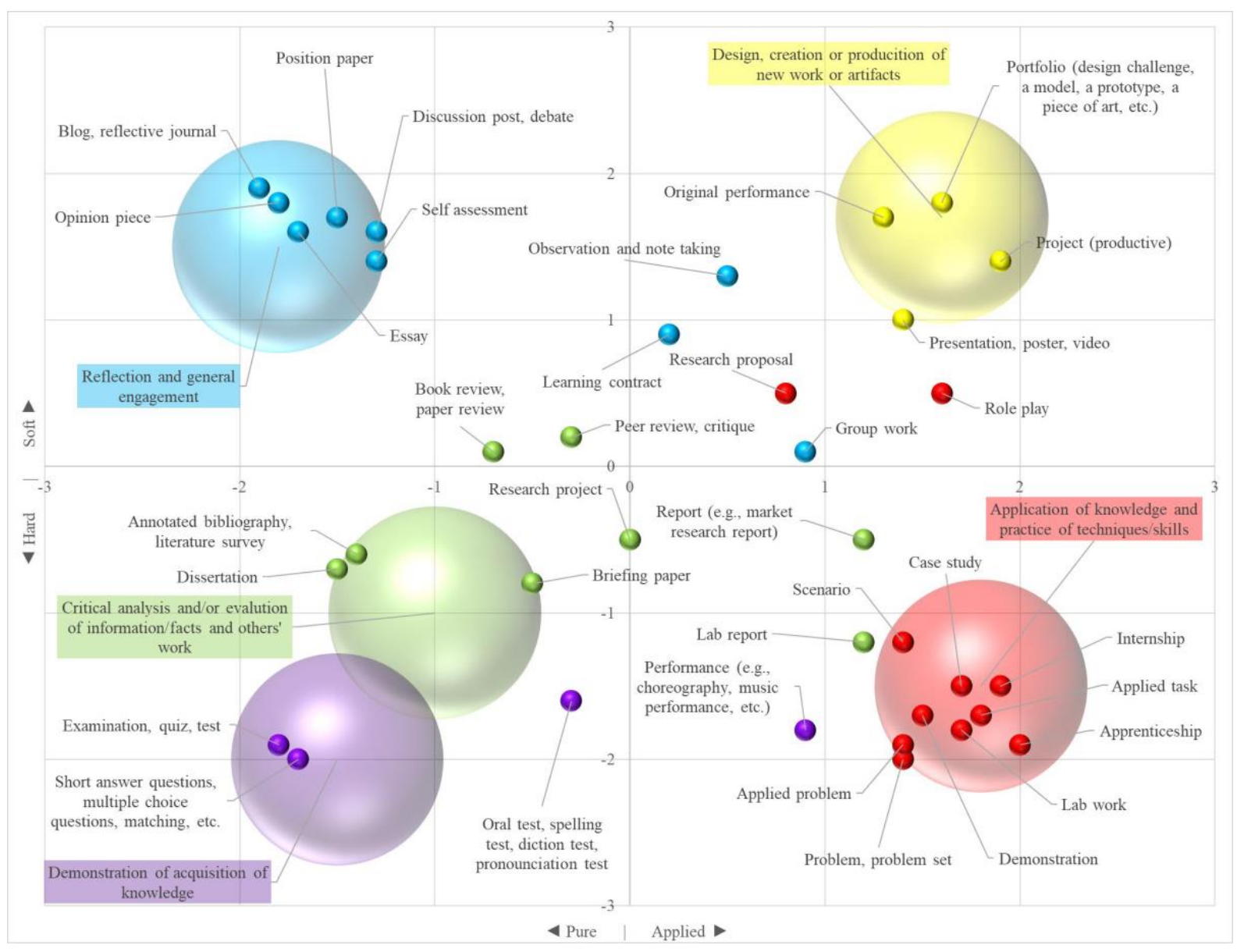

Figure 2: Various assessment methods scattered on the PAHS map

\section{Pure vs. Applied Assessments}

We refer to an assessment method as "Applied" if it requires the student to practice to a degree similar to what is required of a graduate in the discipline. Often, this involves a problem-based learning technique or immersion in a practice environment. Applied assessment methods are often aimed at progressing the student from the theory domain to the practice domain.

It is common to require senior students in a number of academic programs to undergo some sort of apprenticeship, placement or internship, where the students are graded based on their performances in a work- related environment. Applied assessments are often "hands-on" (learning by doing), requiring the application of knowledge in a real-world (or simulated) environment.

A "pure" assessment method, in opposite, does not seek to employ the knowledge as much as it aims to ensure the knowledge or theory is well understood by the student. The contextualisation of the knowledge in a pure task can be well accepted as a hypothesised scenario, while an applied task would seek to contextualise the knowledge within a real (or at least realistic), authentic practice. The assessment methods in Figure 2 are ranging from -2 (purest) to +2 (most applied) on the pure-to-applied axis. 
'Hard' assessment methods are characterised by a clear notion of correct and incorrect, where there is no room for a subjective opinion. It is often the hard assessment types that are easiest to implement for an automated marking since a computer can be programmed to distinguish a right answer from a wrong one. More complex marking strategies exist for tasks such as writing a computer program, which can be done fairly, yet fully automatically. A spelling test, for example, is on the 'hard' side of the spectrum since the student undergoing this assessment is required to correctly spell words - without applying much imagination or creativity in this task - in order to receive a good mark.

'Soft' assessment methods are not concerned much with the truth (right or wrong) but more with the beauty (good or bad) of the resulting work. 'Soft' assessments often involve a great deal of subjective judgement, the assessor's personal impression of the presented work with respect to a defined marking rubric. It is quite hard to exactly quantify the quality of the work, and often, different assessors would suggest a different score to the same work. Such assessments are nearly always marked by human assessors and are not suitable for a programmed automated marking. An essay would normally be considered a "softer" assessment method than a report: An essay is often less structured (or not at all) compared to a report; it seeks to articulate an idea, whereas a report is more factoriented.

\section{Fitness of Assessment Methods to Various Disciplines - Mash-up PAHS Map}

Now that we have considered a set of different academic disciplines and a set of different assessment methods on the PAHS map, it is interesting to see both sets rendered together on the same axes. This can be seen in Figure 3, where the blue dots represent the academic disciplines and the red dots represent the assessment methods. We call this plot the mash-up PAHS map.

At a first glance, one will notice that there are many sensible "matches" between neighboring disciplines (blue) and assessment methods (red). For instance, it is not surprising to find 'Examination, quiz, test' very close to Mathematics since they are both, generally speaking, quite "hard" and "pure". However, this view is too naïve. A closer look into the mash-up PAHS map may raise some doubts regarding its usefulness. For example, one can notice the 'Oral test, spelling test, diction test, pronunciation test' is quite low towards the "Hard" side, whereas 'Languages and literature' is quite high towards the "Soft" side of the HS axis. Similarly, 'Essay' is quite far to the left (pure) whereas 'Business' is quite far to the right (applied), despite essays being quite common in Business degrees.

Furthermore, one may wonder how to use this map. For instance, should the proximity between 'Law' and 'Peer review' be interpreted as if we were to suggest that peer reviews are the most suitable form of assessment for the law discipline? In what follows we reconcile these points of doubt by explaining how learning designers can effectively utilise the PAHS map to their needs.

\section{Prescriptive - No, Inspirational - Yes}

One should indeed be cautious not to assume that there is a one-size-fits-all assessment method for a given discipline. Clearly, each discipline comprises tens or hundreds of sub-disciplines, which can be quite different to one another, thus positioned differently on the PAHS map. An academic degree (often even a research-focused one) in any of the disciplines would require passing several different courses, often varying in the assessment methods used. An assessment method that suits a certain sub-discipline can be inappropriate for another subdiscipline. Moreover, each person is likely to locate the disciplines and assessment methods differently on the PAHS map. It is important to recognise that our framework is not prescriptive, rather, it can be used for the following purposes:

1. Allowing learning designers to appreciate the wide range (spectrum) of assessment methods.

2. Encouraging an informed conversation (e.g., between academics and learning designers) about the suitability of various assessment methods to certain contexts (disciplines, courses, topics, etc.).

3. Providing useful terminology for the conceptualisation and comparison of different assessment methods with respect to the PAHS parameters.

4. Providing a template for adding new map data (and modifying current entries) to suit specific interests.

These purposes highlight the main contribution of the PAHS map: its ability to inspire LDs when designing assessments for any course in any discipline. They can then communicate their rationale to other stakeholders with 
whom they work, including (if beneficial) the learners. We encourage LDs to adapt the PAHS map to their specific needs, even if by merely visualising where they would situate various courses and assessment methods.

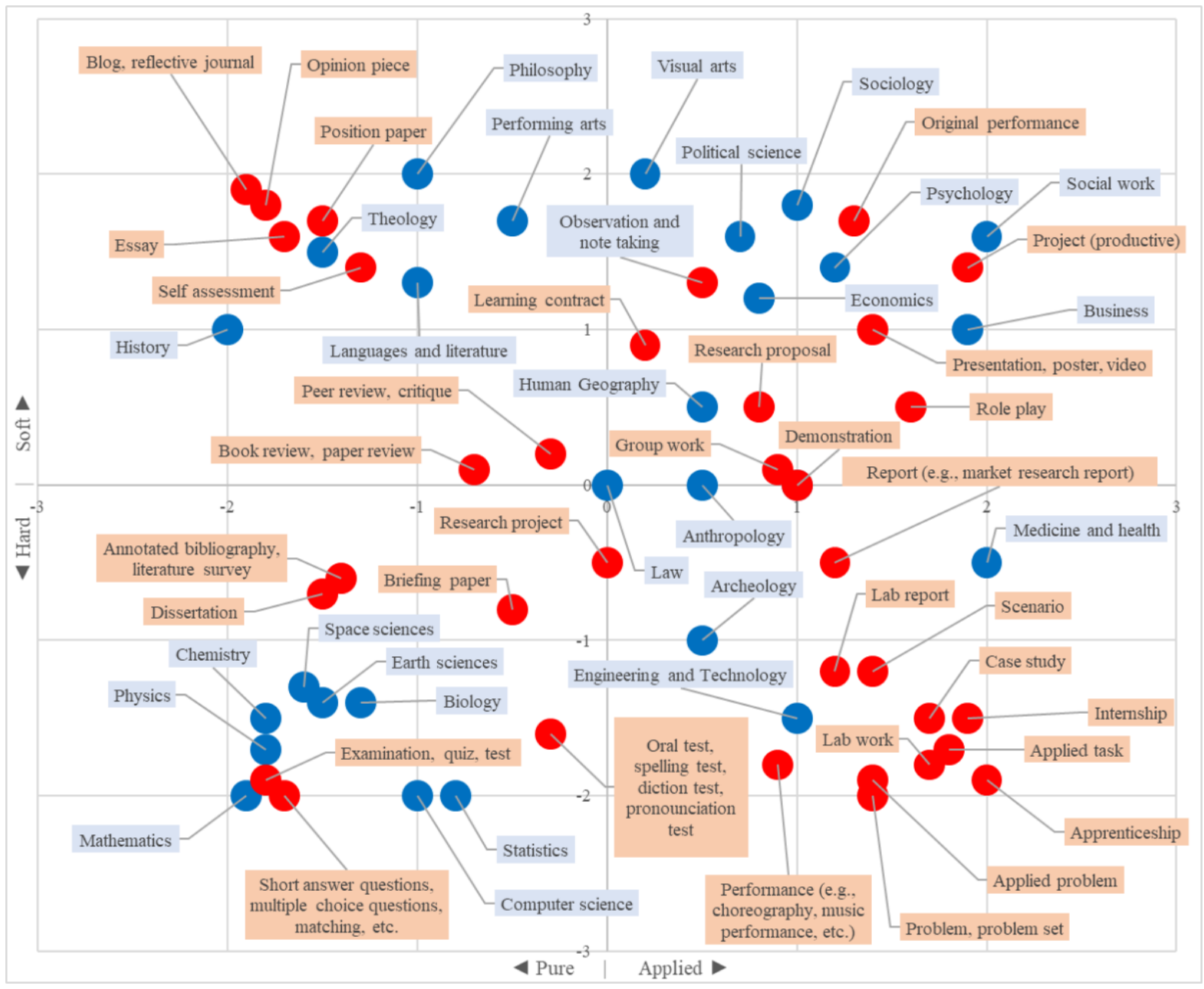

Figure 3: Mash-up of assessment methods and disciplines scattered on the PAHS map

\section{Application of the PAHS Tool - A Case Study}

In the following case study, the course and assessment names and the relative assessment weightings were altered from the originals for the purpose of de-identification. However, all positions on the PAHS map were accurately preserved. This example demonstrates how using the PAHS map can both provide insights into how well-suited specific assessments are to certain courses and facilitate the sharing of these insights amongst stakeholders working on a given course.

An LD at Keypath was involved in the creation of the course "Infographics: Theory and Practice". We have asked the LD to rate both the course (overall) and each of its three assessments in terms of Pure-Applied and Hard-Soft using a designated questionnaire. The LD was also asked (via the questionnaire) to reflect on each assessment's suitability to the course (either very, somewhat, or not quite suitable/useful), their personal familiarity with the course contents, and any other design considerations that shaped the assessments.

The results are summarised in Figure 4. The ranking of the course (based on the intended learning outcomes) is shown as a small red dot. The three assessments, weighing $25 \%$ (a set of weekly online tests composed of multiple-choice and short-answer questions), 30\% (infographics narrative video presentation and a critique paragraph), and $45 \%$ (create your own infographic: designing and producing a compelling infographic for a real body of information) are represented by the bigger circles with areas corresponding to weighting. The little black dot shows the location of the weighted average of the three assessments.

Figure 4 clearly displays the gap between the red and the black dots, calling for either a change of perspective 
(moving the red dot) or redesign of assessments (moving the black dot) in future iterations of the course. This gap can be used as a discussion tool between the LD and the academic, with the aim of better aligning the intended learning outcomes with the assessments used. The academic could be shown the same questionnaire and the two different perspectives (that of the LD and that of the academic) could be used to communicate where change is needed. For instance, Figure 4 shows that according to the LD's viewpoint, Assessment 1 (online tests) is least aligned towards the overall positioning of the course on the PAHS map, and this is also reflected in their ranking of suitability: only assessment 1 was ranked as somewhat suitable/useful to the course, whereas the other two were ranked suitable/useful. To note, this is only the perspective of the LD, and in the future, we intend to collect similar data from the various stakeholders in a multitude of courses, thus providing a better reasoning for assessment design and re-design.

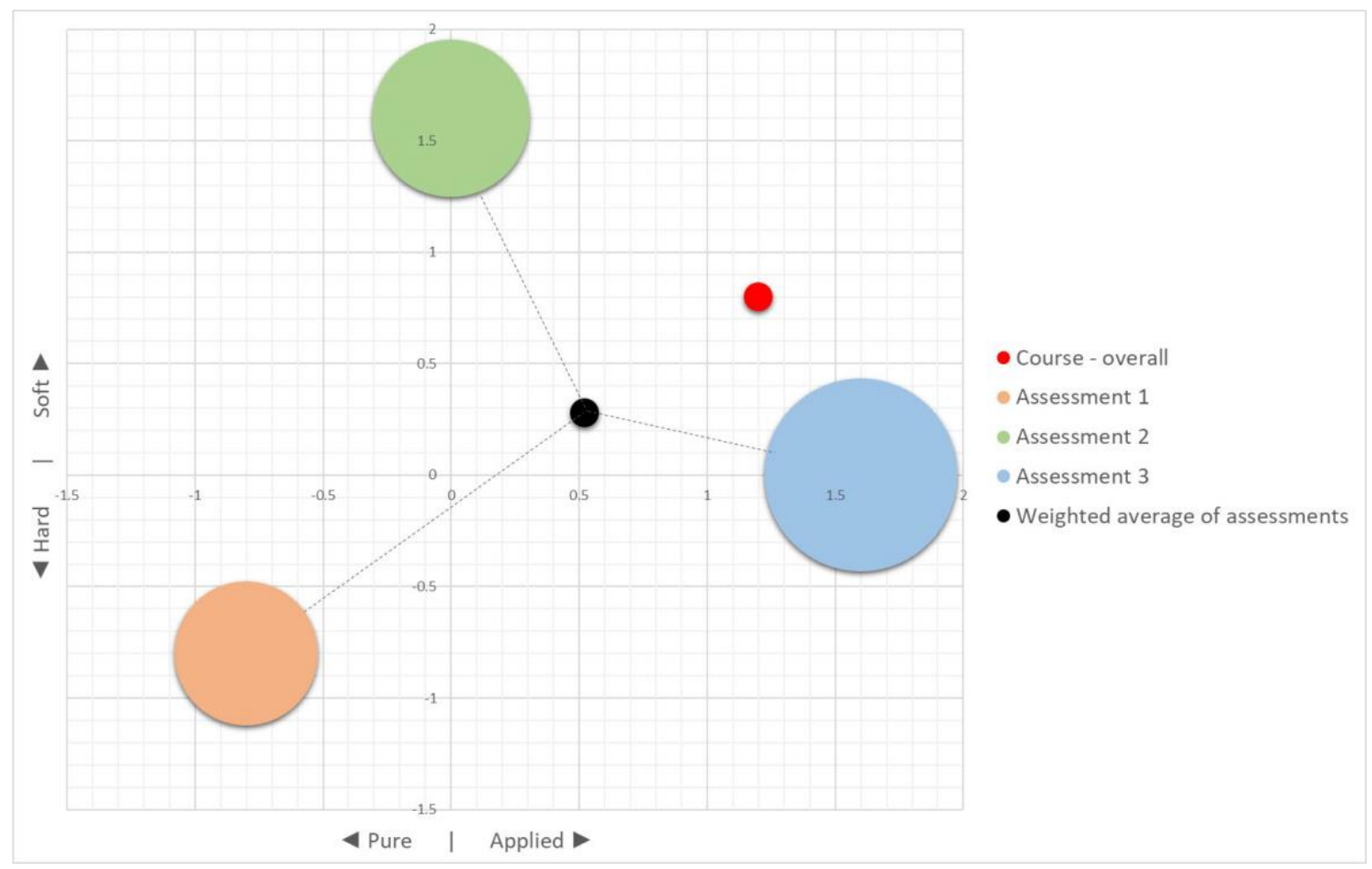

Figure 4: Using the PAHS map to reflect on assessment design in a specific course

\section{Conclusions}

We have presented a framework for characterising assessment methods and disciplines in a way that allows discussing the suitability of assessment methods with a discipline in question. The framework uses the PAHS map, with elements scattered within its four quadrants: (1) Pure and Hard; (2) Pure and Soft; (3) Applied and Hard; (4) Applied and Soft. It is useful to identify where a certain course (or module) fits inside the map to try and identify possible assessment methods which could be useful to address the learning outcomes of the course (or module). A similar rationale is used to locate assessment methods within the map; therefore, it is possible to obtain alignment between the learning outcomes achieved by undergoing the assessment and the intended learning outcomes of the course.

We acknowledge that the PAHS map should not be used algorithmically and a great deal of discretion should be applied by the user. The user, often an LD who might be unfamiliar with the contents and epistemological beliefs associated with a discipline, is encouraged to access the source file with the generated plots and amend the data and/or add new data to the plots in order to utilise this tool. For instance, an LD working on a set of courses in a Cyber Security program can scatter the different courses within the program on the PAHS map and then discuss their choices with the relevant academic stakeholders, thus generating a common language in selecting suitable assessment methods within the various courses.

One noticeable idea that resulted from this work is the possibility to use the PAHS map for positioning individual intended learning outcomes (instead of disciplines) and positioning action verbs that define the assessment tasks (instead of the assessment methods). In this way, the alignment or misalignment between the various elements on 
the map could be more obvious and direct. This, however, is left for future work.

\section{References}

Alexander, P. A. (1992). Domain knowledge: Evolving themes and emerging concerns. Educational Psychologist, 27(1), 33-51. https://doi.org/10.1207/s15326985ep2701_4

Alexander, P. A., \& Judy, J. E. (1988). The interaction of domain-specific knowledge in academic performance. Review of Educational Research, 58(4), 375-404.

Anderson, L. W., \& Krathwohl, D. R. (Eds.). (2001). A Taxonomy for Learning, Teaching, and Assessing: A Revision of Bloom's Taxonomy of Educational Objectives. Allyn \& Bacon.

Biglan, A. (1973a). The characteristics of subject matter in different academic areas. Journal of Applied Psychology, 57(3), 195-203. https://doi.org/10.1037/h0034701

Biglan, A. (1973b). Relationships between subject matter characteristics and the structure and output of university departments. Journal of Applied Psychology, 57(3), 204-213. https://doi.org/10.1037/h0034701

Bisset D. (2019). Role of educational designers in higher education institutions. In C. Bossu \& N. Brown. (Eds.). Professional and Support Staff in Higher Education. University Development and Administration. Springer. 119. https://doi.org/10.1007/978-981-10-1607-3 14-3

Buehl, M. M., \& Alexander, P.A. (2001). Beliefs about academic knowledge. Educational Psychology Review, 13(4), 385-418. https://doi.org/10.1023/A:1011917914756

Donald, J. G. (1995). Disciplinary differences in knowledge validation. New Directions for Teaching and Learning, 64, 6-17. https://doi/org/10.1002/t1.37219956404

Engineers Australia. (2019). Stage 1 Competency Standard for Professional Engineer. Retrieved from https://www.engineersaustralia.org.au/sites/default/files/2019-11/Stage1_Competency_Standards.pdf

Gibbs, G. (1999). Using assessment strategically to change the way students learn. In S. Brown \& A. Glasner (Eds.). Assessment Matters in Higher Education: Choosing and using diverse approaches. SRHE and the Open University Press, 41-53.

Gibbs, G., \& Simpson, C. (2004). Conditions under which assessment supports students' learning. Learning and Teaching in Higher Education, 1, 3-31.

Hofer, B. K. (2000). Dimensionality and disciplinary differences in personal epistemology. Contemporary Educational Psychology, 25(4), 378-405.

Hofer, B.K., \& Bendixen, L.D. (2012). Personal epistemology: Theory, research, and future directions. In K. R. Harris, S. Graham \& T. Urdan (Eds.). APA Educational Psychology Handbook, Vol. 1: Theories, Constructs, and Critical Issues. American Psychological Association. 227-256.

Hofer, B. K., \& Pintrich, P. R. (1997). The development of epistemological theories: beliefs about knowledge and knowing and their relation to learning. Review of Educational Research, 67(1), 88-140. https://doi.org/10.3102/00346543067001088

Kember, D., \& Kwan, K. (2000). Lecturers' approaches to teaching and their relationship to conceptions of good teaching. Instructional Science, 28(5/6), 469-490. https://doi.org/10.1023/A:1026569608656

Kniveton, B. H. (1996). Student perceptions of assessment methods. Assessment \& Evaluation in Higher Education, 21(3), 229-238.

Krathwohl, D. R. (2002). A Revision of Bloom's Taxonomy: An Overview. Theory into Practice, 41(4), $212-218$.

Lindblom-Ylänne, S., Trigwell, K., Nevgi, A., \& Ashwin, P. (2006). How approaches to teaching are affected by discipline and teaching context, Studies in Higher Education, 31(3), 285-298. https://doi.org/10.1080/03075070600680539

Mitchell, K., Simpson, C., \& Adachi, C. (2017). What's in a name: the ambiguity and complexity of technology enhanced learning roles. In H. Partridge, K. Davis, \& J. Thomas. (Eds.). Me, Us, IT! Proceedings ASCILITE2017: 34th International Conference on Innovation, Practice and Research in the Use of Educational Technologies in Tertiary Education. 147-151. http://2017conference.ascilite.org/wpcontent/uploads/2017/11/Concise-MITCHELL.pdf

Muis, K. R., Bendixen, L. D., \& Haerle, F. C. (2006). Domain-generality and domain-specificity in personal epistemology research: Philosophical and empirical reflections in the development of a theoretical framework. Educational Psychology Review, 18(1), 3-54. https://doi.org/10.1007/s10648-006-9003-6

Neumann, R. (2001). Disciplinary differences and university teaching. Studies in Higher Education, 26(2), 135146. https://doi.org/10.1080/03075070120052071

Neumann, R., Parry, S., \& Becher, T. (2002). Teaching and learning in their disciplinary contexts: A conceptual analysis. Studies in Higher Education, 27(4), 405-417. https://doi.org/10.1080/0307507022000011525

Päuler-Kuppinger, L., \& Jucks, R. (2017). Perspectives on teaching: Conceptions of teaching and epistemological beliefs of university academics and students in different domains. Active Learning in Higher Education, 18(1), 63-76. https://doi.org/10.1177/1469787417693507

Sambell, K., \& McDowell, L. (1998). The construction of the hidden curriculum: Messages and meanings in the 
assessment of student learning. Assessment and Evaluation in Higher Education, 23(4), 391-402.

Schommer, M. (1994). Synthesizing epistemological belief research: Tentative understandings and provocative confusions. Educational Psychology Review, 6(4), 293-319. https://doi.org/10.1007/BF02213418

Schommer, M., \& Walker, K. (1995). Are epistemological beliefs similar across domains? Journal of Educational Psychology, 87(3), 424-432.

Schommer-Aikins, M., Duell, O. K., \& Barker, S. (2003). Epistemological beliefs across domains using Biglan's classification of academic disciplines. Research in Higher Education, 44(3), 347-366. https://doi.org/10.1023/A:1023081800014

Shulman, L. (2005). Signature pedagogies in the professions. Daedalus, 134(3), 52-59. Shvartsman, R. \& Abblitt, S. (2020). The PAHS map. https://bit.ly/3du5v5s

Slade, C., McGrath, D., \& Greenaway, R. (2018). Professionalisation in academic development: exploring learning designer roles in a changing higher education sector. AdvanceHE teaching \& Learning Conference 2018: Teaching in the spotlight: Learning from global communities, Birmingham, United Kingdom, 3-5 July 2018. AdvanceHE.

Slade, C., McGrath, D., Greenaway, R., \& Parker, J (2019). Emerging third space professionals. 42nd Higher Education Research and Development Society of Australasia Annual Conference, University of Auckland, New Zealand, 2-5 July 2019. University of Auckland.

Snyder, B. R. (1971). The Hidden Curriculum. MIT Press.

Sternberg, R. J. (1989). Domain-generality versus domain-specificity: The life and impending death of a false dichotomy. Merrill-Palmer Quarterly, 35, 115-130.

Trigwell, K., Prosser, M., \& Waterhouse, F. (1999). Relations between teachers' approaches to teaching and students' approaches to learning. Higher Education 37(1), 57-70. https://doi.org/10.1023/A:1003548313194

Wiggins, G., \& McTighe, J. (1998). Understanding by Design. ASCD.

Shavartsman, R. \& Abblitt, S. (2020). A spectrum of assessments. In S. Gregory, S. Warburton, \& M. Parkes (Eds.), ASCILITE's First Virtual Conference. Proceedings ASCILITE 2020 in Armidale (pp. 328-337).

https://doi.org/10.14742/ascilite2020.0118

Note: All published papers are refereed, having undergone a double-blind peer-review process.

The author(s) assign a Creative Commons by attribution licence enabling others to distribute, remix, tweak, and build upon their work, even commercially, as long as credit is given to the author(s) for the original creation.

(C) Shavartsman, R. \& Abblitt, S. 2020 